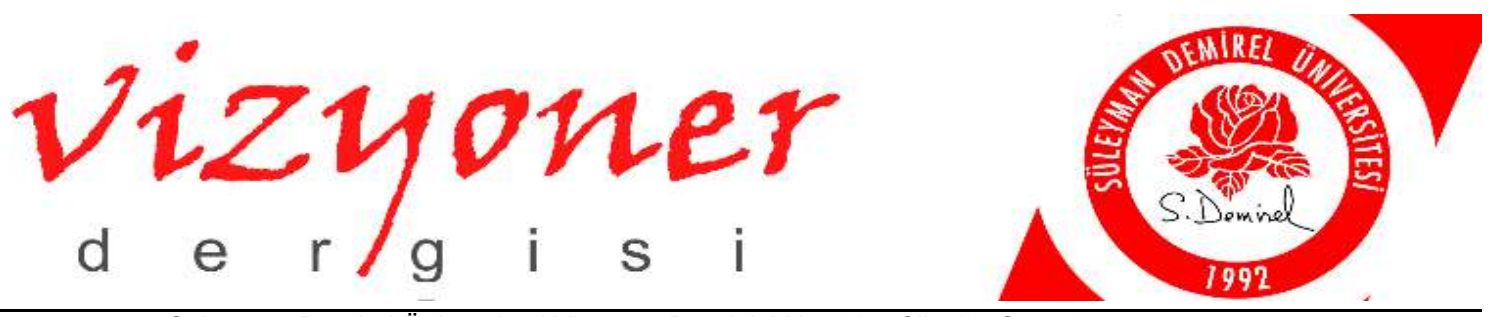

Süleyman Demirel Üniversitesi Vizyoner Dergisi, Yıl: 2019, Cilt: 10, Sayı: 23, ss.15-24.

Suleyman Demirel University Visionary Journal, Year: 2019, Volume: 10, Number: 23, pp.15-24.

\title{
FARKLI BAKIŞ AÇISI KAZANMAK ICÇIN BEYİN FIRTINASI MODELLERİ
}

\section{MODELS OF BRAINSTORMING FOR GAINING A DIFFERENT POINT OF VIEW}

\author{
Prof. Dr. Mustafa Şeref AKIN ${ }^{1}$
}

Öz

Einstein'ın sorunların çözümüyle ilgili önemli bir tespiti, problemlerin onları oluşturan aynı düşünce düzeyiyle çözülemeyeceği yönündedir. Öyleyse başka bir bakış açısı nasıl yakalanacak? Bunun için farklı bakış açısını çağrıştıracak metodolojik beyin firtınası metotları mevcut mu? Bu makalede “alternatif dünyalar, zıtlıklar, 10'un gücü” beyin firtınası metotları ile mevcut unsurlar farklı bakış açılarıyla birleştirilip yeni çözümler üretme yolları gösterilecek. Video kiralama, eğitim, bankacılık, hastane, catering, dondurulmuş gıda, ATM, birimlerin yeniden organizasyonu üzerine farklı sektörlerden örnek çalışmalar ele alınacak. İnsanları farklı düşünmeye zorlamak satrancı hiç bilmeyen bir kişiye "Rakibini mat et." demektir. Çerçeve dışına bakılmadan önce çerçevede (ve içinde) sonrasında çerçevenin dışında nereye bakılacağının araştırılması gerekir. Beyin fırtınası öncesi ana husus problemin ve unsurların tespitidir. Bu unsurların çözümü için kaynak mekânların arayışına geçilir. Sonrasında beyin firtınası yapılır. Rastgele iki farklı kavramın birleştirilmesi ile aşılama yapılmaya çalışılmaz.

Anahtar Kelimeler: İnovasyon, Farklı Düşünme, Beyin Fırtınası, Alternatif Dünyalar, Zıtlık, 10’un Gücü.

JEL Sinıflandırma Kodları: M1.

\begin{abstract}
Einstein's remarkable analysis on the solution of the problems is that "Problems cannot be solved by the same level of thinking that created them." So how another perspective is captured? For that purpose, is there any methodological brainstorming method that would suggest a different point of view? In the article, "alternative world, contradictory, power of ten" methodologies of brainstorming are explored to combine the old things with new perspectives. By using these brainstorming methods new ideas for video renting, education, banking, healthcare sector, catering, frozen food, ATM and re-organization are developed. Asking people to think differently is like to force someone who does not how to play chess to "checkmate". Before looking out of the box, it is necessary to determine where to look inside and then outside the box. Before the brainstorming session, the main issue is the determination of the problem and its components. Then, for the solution of these components the search of resources is initiated. Thereafter, brainstorming is realized. Two unrelated concepts are not randomly chosen and combined.
\end{abstract}

Keywords: Innovation, Different View, Brainstorming, Alternative World, Contrast, Power of Ten.

JEL Classification Codes: M1.

\footnotetext{
Erzincan Binali Yıldırım Üniversitesi, İktisadi ve İdari Bilimler Fakültesi, İktisat Bölümü, mustafa.akin@erzincan.edu.tr, https://orcid.org/0000-0002-1850-9118
} 


\section{GİRIŞ}

Einstein'ın sorunların çözümüyle ilgili önemli bir tespiti, problemlerin onları oluşturan aynı düşünce düzeyiyle çözülemeyeceği yönündedir (Good Read, 2018). Zaten farklı düşünülebilseydi problem de kalmazdı. Öyleyse başka bir bakış açısı nasıl yakalanacak? Bunun için farklı bakış açısını çağrıştıracak metodolojik beyin firtınası metotları mevcut mu? Bu çalışmada beyin firtınası yöntemlerinden "alternatif dünyalar, zıtlıklar, 10'un gücü” ile farklı bakış açılarının nasıl yakalanabileceği tartışılacak (Kumar, 2012: 12, Luma Institute, 2012: 21; 2014: 45). Her metodun tanımı, sistematiği ve örneklerle çözümleri verilecek.

İşletmeler zor bir problem çözerken sıkışıp kalır, bunu aşmanın yollarından biri de tamamen alternatif, zıt veya abartılı bir bağlamdan ilham aramaktır. Alternatif dünyalarda başka sektörlerden ve yaratıcı yaklaşımlardan metaforlar kullanılır. Zıtlıkta, problemi doğuran üretim süreci adım adım ele alınır, aralarından bir veya birkaçının zıddı ile tekrar süreç oluşturulur. 10'un gücünde ise kaynakların 10 kat artırılması veya azaltılması sonucunda ne nasıl yapılır tartışıldıktan sonra, mevcut kaynaklarla aynı sonucun elde edilmesine gayret gösterilir.

Kimsenin düşünmediği yeni bir yaklaşımla soruna çözüm getirme inovasyon ile ilgili yanlış bir algıdır. Çünkü yeni zannedilenlerin hiçbiri yeni değildir. İnovasyon var olan çözümleri, fikirleri ve kavramları birleştirerek yeni bir çözüm getirmektir (Sutton, 2007: 44). Öyleyse var olan fikirlerle mevcut problem nasıl birleştirilecek? Eskileri yeni bir yolla birleştirmek kolay gibi görünen bir reçete aslında ama çok ciddi bir yönlendirme, adım adım takip edilmesi gereken bir süreci de beraberinde getirir (Sutton, 2004: 34; Sutton, 2007: 42). Bu makalede "alternatif dünyalar, zitlıklar ve 10'un gücü" metotları ile eski unsurları birleştirip yeni çözümler üretmenin yolları gösterilecek (Kumar, 2012: 45; Kelley, 2005: 77; Kelley ve Kelley, 2014: 103).

İnovasyonda cevap verilmesi gereken soru fikrin neden mevcut çözüme göre orijinal olduğudur. Bu noktada inovasyonu, icat etmek olarak algılamamak önemlidir. Yenilikçi ve farklı olan, pazarda var olmayan ve müşterinin gözünde ürüne katma değer katan her gelişme inovasyondur (Drucker, 2007: 76-81).

Farklılık katmak ile değişim arasında da fark vardır. Örneğin, yöneticilerin aynı şeyi yapmaktan sıkılarak, yaptıkları işe yenilik katmaları bir değişimdir. Ama önemli olan bu yeniliğin müssterilere bir şey katıp katmadığıdır. Bu durumda yeniliğin üreticinin gözünde değil, müşterinin gözünde bir ilerleme ifade edip etmediği ve bunun için müşterinin ek bir ücret ödemeyi kabul edip etmeyeceği ana kriterleri oluşturur.

Sektörde mevcut firmaların avantajlarını kırmak çok güçtür. Piyasadaki birçok kurum yeni firmanın gelişini önceden engeller (Porter, 2007: 104).

Rakip firmaların avantajları şunlar olabilir:

- Ölçek ekonomisi

- Marka avantajı ve ürün farklılaştırılması

- Sermaye gerekleri

- Geçiş maliyeti

- Dağıtım kanallarına erişim

- Lisans ve patent

- Ham maddelere rahat erişim

- Elverişli yerler

- Çıkış maliyeti

Bu nedenle fikrin orijinalliği statükoyu değiştirmek açısından çok önemlidir. Bu bağlamda beyin firtınasının özü inovatif çözümlerin ortaya çıkması için durumun farklı bir biçimde karakterize edilmesidir. Metotlara uyulmadı $\breve{g} 1$ takdirde beyin firtınasından alınan fayda ayrı ayrı kişilerin tek başına fikir üretmesinden oluşacak toplam miktardan ve kaliteden düşüktür (Owens, 2011: 101, Diehl ve Strpebe, 1987: 480). Beyin firtınalarında metodoloji olmaksızın süreç, katılımcıların birbirlerini bloke ettikleri bir kaotik ortama dönüşür. Bu noktada, alternatif dünyalar, zıtlıklar ve 10'un gücü metotları işletmelerin arzu ettiği farklı bakış açılarının elde edilmesinde ve inovatif fikirlerin üretilmesinde etkin bir yöntem getiriyor (Kumar, 2012: 67). 


\section{FARKLI BAKIŞ KAZANMA: BEYINN FIRTINASI METOTLARI}

\subsection{Alternatif Dünyalar Metodu}

Yenilik geçmişteki deneyimlerden faydalanıldığında ve onlardan benzetmeler ve kombinasyonlar kurgulandığında ortaya çıkar.

Beyin firtınasında ekip, işi unsurlara (dağıtım, ödeme, lojistik, finansman vb.) böler. Unsurlardaki problemler tanımlanır. Her unsura yönelik çözüm için kullanılacak başka şirketlerin, kurumların, organizasyonların, teknolojilerin konuyla ilgili kaynak fikri belirlenir (Şekil 1). Burada önemli bir husus, ilham alınacak kaynağın araştırılması veya ekibin geçmişinde (repertuvarında) mevcut olması yönündedir (Higgins vd., 2014: 55; Kumar, 2012: 88, Beckman ve Barry, 2007: 67; Brown, 2009: 77; Kelley, 2000: 125). Bu çalı̧̧manın başarılı olması için benzetilmek istenen kavramların listesi yapıldıktan sonra firsatlar aranır.

Alternatif dünyalarda beslenilecek şirketlerin/organizasyonların keşfedilmesi için çokça okumak, araştırmak, bilgi ve donanım sahibi olmak gerekir.

Alternatif dünyalarda, hangi unsurdaki problemin çözüleceği ve hangi kaynaktan istifade edileceği iyi ifade edilmelidir. Örneğin, küçük bir aile şirketinin dev bir holdingden ilham almaya çalışması anlamsızdır. Çünkü aile şirketinin problemleriyle dev bir holdingin problemleri farklıdır. Aile şirketinin finansman probleminde "Dev holding olsaydı ne yapardı?" diye sorulamaz. Ayrıca alternatif dünyalar metodunu uygularken kendi sektörümüzden uzaklaşma gayreti içindeyizdir. Yani başka düzlemlerden cevap aranır. Aile şirketinin finansman problemi için yeni kurulan bir vakfın yüksek miktarda kaynak bulmayı başarması ve gerçekleştirme yolu bir ilham olabilir.

Şekil 1. Alternatif Dünyalar

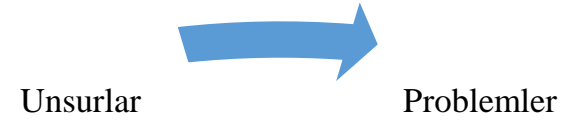

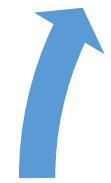

Kombinasyon
Problemler

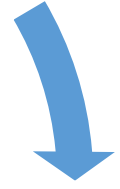

Repertuvar/Araştırma
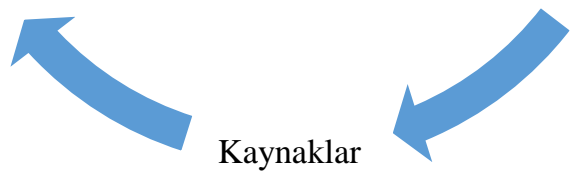

Kaynak: (Kumar, 2012)

\section{Kullanılırken dikkat edilmesi gereken hususlar:}

- Araştırılması için bir sorun belirlenir.

- Grup oluşturulur.

- Sorunların listesi yapılır ve sorun parçalara bölünür.

- Repertuvara dönülür ve kaynak çc̈zümler aranır. Düzlemin mevcut sektörden çok farklı bir dünyaya ait olmasina dikkat edilir. 
- Başka düzlemler (sektör, meslek, mekân, işletme, marka vb.) belirlenir.

- Her düzlemin anahtar ögeleri belirlenir.

• “Bu sorun bu düzlemde olsa nasıl çözülür?” gibi sorular yöneltilir.

- Yeni perspektiften farklı fikirlere ulaşılmaya çalışılır.

- Kombinasyonlar yapılır.

Dört ayrı sektörde nasıl uygulanabileceğinin gösterilmesi üzerine örnek çalışmalar yapılacak.

\subsubsection{Video Kirala Sektöründe Netflix}

1997'de Reed Hasting video kiralama sektöründe Netflixi kurgularken sektör devi Blockbusterdaki problemlerin unsurlarını analiz eder: İş modeli, ödeme sistemi (abonelik) ve dağıtım sistemi. Hasting sonrasında da mevcut video zincirlerini iflas ettiren şirket Netflixi kurar.

Hasting video kiralama işini mevcut sektör devi Blockbusterdan, spor merkezlerinden, Amazondan ve yeni DVD teknolojisinden alarak inovasyonu kurgular (Tablo 1). Her şirketten veya teknolojiden işine yarayan fikirleri harmanlar (Peterson, 2013; Bushey, 2014). Video kiralama iş modelini Blockbusterdan alır. Ödeme sistemini oluştururken spor merkezlerine üyelikte kullanılan aylık abonelik sisteminden faydalanır. Amazondan e-ticaret, ödeme ve kargolama hizmetlerini alarak yeni bir kombinasyon kurgular. Böylece müşteri, abone ücretini online olarak ödeyerek kargodan videolarını alabilir. Kargo maliyetini azaltmak için DVD’nin hafifliğinden faydalanır. DVD teknolojisinin gelişmesi sayesinde daha hafif bir video daha ucuza kargolanır.

Video kiralamanın, spor merkezinin, e-ticaretin, DVD'nin özellikleri yazılırsa farklı birçok kombinasyon kurulabilir. Ancak burada önce unsurlar (problemin kaynağı) belirlenip sonrasında kullanılabilecek sektörler araştırılmalıdır. Örneğin, DVD teknolojisi filmleri daha hızlı kaydedebilir ama bu özellik kullanılmaz. Hastings video dükkânının iş modelinin özellikleri alınır ama fiyatlama spor merkezi aboneliğine göre yapılır. Spor merkezlerine üyelikte kullanılan kart sisteminden faydalanılmaz.

Tablo 1. DVD Kiralama Online Sipariş

\begin{tabular}{|c|l|c|c|c|c|}
\hline \multicolumn{2}{|c|}{} & \multicolumn{4}{c|}{ Kaynaklar } \\
\cline { 2 - 6 } \multicolumn{2}{c|}{} & Blockbuster & Spor Merkezi & Amazon e-ticaret & DVD Teknolojisi \\
\hline \multirow{3}{*}{ Unsurlar } & İş Modeli & $\mathrm{X}$ & & $\mathrm{X}$ & \\
\cline { 2 - 6 } & Ödeme Sistemi & & $\mathrm{X}$ & $\mathrm{X}$ & $\mathrm{X}$ \\
\cline { 2 - 6 } & Dağıtım Sistemleri & & & $\mathrm{X}$ & $\mathrm{X}$ \\
\hline
\end{tabular}

Kaynak: (Peterson, 2013; Bushey, 2014)

Sonuçta, müşterilerin video dükkânlarına gitme zahmeti (dağıtım sistemi), videonun kiralanmasıyla ortaya çıkan zaman kaybı ve zamanında geri getirilmediğinde alınan ceza (ödeme sistemi) ortadan kalkar. Netflixte müşteri online sipariş verir, müşteriye video postalanır, müşteriden aylık abonelik ücreti alınır. Video geri gönderildiği takdirde yeni video alınabilir. Sonuçta Blockbuster gelişmeleri çok geç takip ederek sektörü Netflixe kaptırır ve dev firma iflas eder (Peterson, 2013; Bushey, 2014). Netflix ise yoluna önce internet üzerinden online video seyrettirerek sonrasında kendi prodüksiyonunu yapan bir şirket olarak yeni bir sektör oluşturarak devam eder.

\subsubsection{Kalabalık Sınıfta Dersler Etkin Bir Şekilde Nasıl Verilir?}

Kalabalıklığın getirdiği sorunun unsurlarına bakıldığında bunlar ders materyali, teknoloji, eğitim, notlama ve kişisel ilgi olarak görülür. Eğitim kurumunun sorununun çözümü için, hizmet sektöründen üç şirketin çözüm yöntemleri düşünülebilir: McDonalds/Starbucks/Swissotel. 
Süleyman Demirel Üniversitesi Vizyoner Dergisi, Yıl: 2019, Cilt: 10, Sayı: 23, ss.15-24.

Suleyman Demirel University Visionary Journal, Year: 2019, Volume: 10, Number: 23, pp.15-24.

Tablo 2. Akademik Hayattaki Sorun: Kalabalık Sınıflarda Dersin Etkin Anlatımı

\begin{tabular}{|c|l|c|c|c|}
\hline \multicolumn{2}{|c|}{} & \multicolumn{3}{c|}{ Kaynaklar } \\
\cline { 3 - 5 } \multicolumn{1}{|c|}{} & McDonald's & Starbucks & Swissotel \\
\hline \multirow{4}{*}{ Unsurlar } & Ders materyali & $\mathrm{X}$ & & \\
\cline { 2 - 5 } & Teknoloji & $\mathrm{X}$ & & \\
\cline { 2 - 5 } & Eğitim & $\mathrm{X}$ & $\mathrm{X}$ & \\
\cline { 2 - 5 } & Notlama & $\mathrm{X}$ & $\mathrm{X}$ & \\
\cline { 2 - 5 } & Kişisel ilgi & & & $\mathrm{X}$ \\
\hline
\end{tabular}

Bu sorunu McDonald's/Starbucks/Swissotel olsaydı nasıl çözerdi? Burada fast-food zinciri McDonald's firması bütün olarak alınmıyor (www.mcdonalds.com). Onların çalışma yöntemlerinden ilham alınıyor.

McDonald's nasıl bir organizasyonu temsil ediyor?

Üretim: Arka planda çalışanlar rutin olarak, elektronik ortamda gelen siparişi hazır gıdayla üretirler.

Standardlaşma: Bütün faaliyetler belli ve basitleştirilmiş kurallar çerçevesindedir.

Menü: Tek tek ürün yerine menüler vardır. Kasiyer tek tuşa basarak siparişi geçer.

Demek ki McDonald's gibi düşünüldüğünde ders materyalleri, eğitim ve notlama standartlaşmış, hazır ve seri olacaktır. Teknoloji desteğiyle seri ödev verilecek ve notlanacaktır. McDonald's modelinde standarlaştırılmış eğitim modeli seri şekilde, belli konularda ve öğrencilere gereken bilgi kadar çoklu seçenekli testlerle yüklenebilir.

Starbucks nas1l bir organizasyonu temsil ediyor (www.sarbucks.com)?

Ortak Üretim: Kısmen çalışanlar kısmen de müşteriler üretiyorlar.

Ortam: Herkes kendi masasında oturuyor. Oturma üniteleri rahattır.

Menü: Ürünler daha çeşitlendirilmiş ama sınırlıdır.

Starbucks modeline göre öğrenciler de kendi kendine öğrenme ve öğretmeni destekleme sürecine girmeliler. Eğitimde öğrencilerden gruplara ayrılıp, örnek sorudan ve cevaptan faydalanıp kendi başlarına yeni sorunu çözmeleri istenebilir. Notlamada ise öğrencilerin diğer öğrencilerin ödevlerini ve sınavlarını okumaları ve notlamaları sağlanabilir.

Swissotel nasil bir organizasyonu temsil ediyor (www.swissotel.com)?

Ortak Üretim: Kişileştirilmiş.

Ortam: Herkes kendi masasında oturuyor. Oturma üniteleri rahattır.

Menü: Ürünler çeşitlendirilmiş ve 7/24 hizmet vardır.

Swissotel kişileştirilmiş ve özenli olma, müşteri tatminini en üst seviyede tutma arzusunu temsil ediyor. Swissotelden esinlendiğinde yardımcı öğretmenler vasıtasıyla kalabalık derslerin yoğun pratik uygulama saatleri sınıflara bölünür. Her öğrencinin konuyu küçültülmüş sınıflarda anlaması pekiştirilir. Okuldaki bir öğretmen gerideki öğrencilere yönelik temel dersleri özel olarak vermek ile görevlendirilebilir (Tablo 2).

\subsubsection{Bankacılıkta Daha İyi Bütçeleme}

Finans sektöründeki yoğun rekabetten dolayı, bankalar inovatif projeler geliştirmede yarışıyorlar. Bir banka genç insanlar için bütçeleme konusunda yardımcı olmak üzere bir proje geliştiriyor. Mevcut çözümler para yönetiminin mekanikliği üzerinde dururken, bu platform sorumlu bütçe yapan birer yetişkin hâline gelmeleri için onlara sürekli destek ve motivasyon sağlıyor. 
Banka ekibi bankacılık hizmetlerinden faydalanan veya faydalanmayan çeşitli kişilerle etnografik araştırma yapıyor (Kumar, 2012). Bütçeleme problemi iki unsurda toplanıyor: Takip etme ve motivasyon. Bu unsurlara yönelik çözümler ortaya çıkarmak için alternatif dünyalar metodu deneniyor. Sağlık ve diyet merkezlerinde kullanılan kaynaklar takip etme ve motivasyon ile ilişkilendiriliyor (Tablo 3). Kilo takip programlarında yemeklerden kazanılan kalori ile spor yapılarak kaybedilen kalori günlük olarak sayılarak ve hedefe olan uzaklığı gösterilerek kilo vermeleri için insanlar motive ediliyor. Bu bütçe takip programı ile, tıpkı kilo takip sisteminde olduğu gibi, kazanç ve harcamalar günlük olarak bütçelerdeki amaçlara ulaşılması için ilişkilendiriliyor.

Tablo 3. Bankacılıkta Bütçeleme

\begin{tabular}{|c|c|c|}
\hline & Kaynaklar \\
\hline & & Diyet programı \\
\hline \multirow{2}{*}{ Unsurlar } & Motivasyon & $\mathrm{X}$ \\
\hline & Takip etme & $\mathrm{X}$ \\
\hline
\end{tabular}

\subsubsection{Sağlıkta Hataları Azaltma}

Bir sağlık kuruluşu acil servisteki ilaç verme süreçlerinde yaşanan bir problemi önlemek için havacılık ve araba yarışları süreçlerindeki kaynakları alıyor. Sağlık kuruluşunda ilaç vermeyle ilgili kişiler olan doktorlar, hemşireler, yöneticiler ve hastalarla görüşülüyor. İki ana unsur tespit ediliyor: Kaosun engellenmesi ve takip.

Hastane ekibi uçak eğitim merkezini ziyaret ediyor. Uçak bakım teknisyenleri kontrol listesini anlatıyorlar. Güvenlik dışında, uçak kalkışından önce her türlü konuşma yasaklanıyor ve listedeki en küçük detayın bile tek tek üzerinden geçiliyor. Kaotik ve stresli ortamı dizayn etmek için Formula 1 yarışlarındaki lastik değiştirme uzmanları takip edilerek yeni ilaç düzenleme sistemi kurgulanıyor. 4 adet lastik değiştirme hızı 6 saniye olan bu ekiplerin, kaosu düzenlemek için öncesinde nasıl hazırlandıkları tespit ediliyor.

Beyin fırtınasında, ilaç hazırlamakla ilgili kurallar ortaya konuyor. İlaç hazırlama bölgesi ve zamanı "steril kokpit" alanı ilan edilerek uçak bakımında ve lastik değiştirmedeki aynı sıkı kurallar uygulanmaya başlanıyor. (Tablo 4).

Tablo 4. Sağlık Hataları Azaltma

\begin{tabular}{|l|l|c|c|}
\hline \multicolumn{2}{|c|}{} & \multicolumn{2}{c|}{ Kaynaklar } \\
\cline { 3 - 4 } \multicolumn{2}{|c|}{} & Uçak Bakım & Formula 1 \\
\hline \multirow{2}{*}{ Unsurlar } & Takip etme & $\mathrm{X}$ & \\
\cline { 2 - 4 } & Kaos & $\mathrm{X}$ & $\mathrm{X}$ \\
\hline
\end{tabular}

Kaynak: (Kumar, 2012)

\subsection{Zitlıklar}

Beyin fırtınasında yeni çözümleri tetikleyen bir metot da zıtlıkları ortaya koymaktır. Zıtlıkları oluşturmak için önce iş tanımları, planlar ve süreçlerdeki adımlar yazılır (Brown, 2008: 57; Brown, 2009: 125; Liedtka \& Ogilvie. 2011, Luma, 2012, 2014, Liedtka vb., 2014, 2013). Sonra da zit kavramlar düşünülür.

Gaye bütün süreci değiştirmek değil, beyin fırtınası ekibi olarak bir ya da iki parçanın zıddını kullanarak diğer değiştirilmemiş olanlarla beraber yeni kombinasyonlar oluşturmaktır. Tüm sistemi değiştirmeye çalışmak kaos getirir.

\section{Kullanılırken dikkat edilmesi gereken hususlar:}

- Önce iş tanımları, planlar ve süreçlerdeki adımlar yazılır.

- Bütün sürecin zıddı bulunmaya çalışılmaz.

- Bir ya da iki adımın zıddı yerleştirilip diğer adımlarla yeni kombinasyonlar oluşturulur. 


\subsubsection{Catering}

Restoran işindeki süreci inceleyelim: Müșteri restorana gelir, siparişini verir; sipariş hazırlanır, yemek sunulur, müşteri ödeme yapar. Burada süreçteki adımlardan biri olan müşterinin restorana gelmesi zıddıyla değiştirildiğinde "Restoran müşteriye gitsin." ile yeni bir iş modeli ortaya çıkar.

Fiziksel iş akımında yemekler sunum yeri olan restorandan alınıp müşterinin istediği başka bir favori mekânda sunulduğunda catering hizmeti doğuyor. Catering hizmet yöntemi yüksek maliyetli olan kiradan tasarruf edilmesini sağlarken, yemekleri uzun süre sıcak muhafaza eden sistemlerin ve yeni diyet programlarının ortaya çıkmasını (Diyet yemeklerini catering firması gönderiyor.) tetikliyor.

Şekil 2. Restoran İş Süreci Adımları

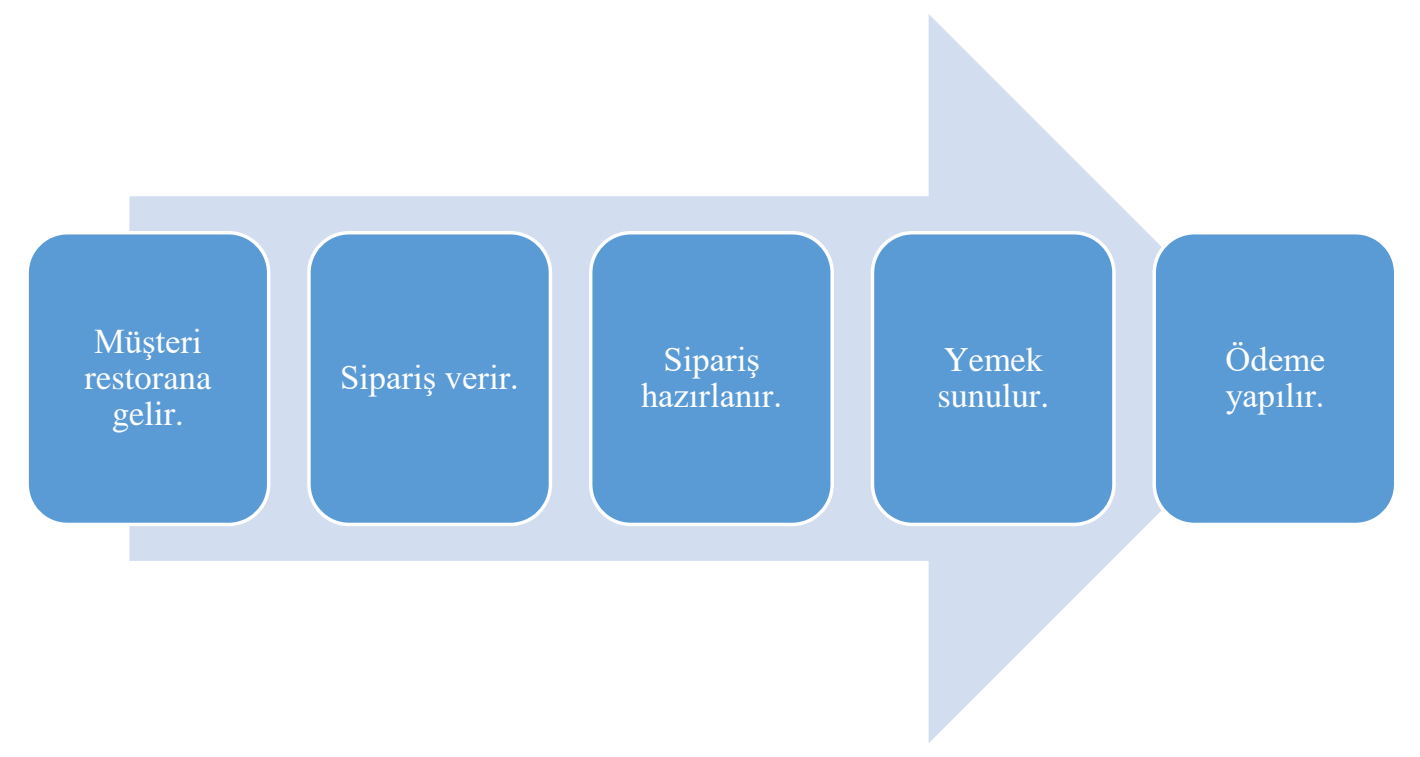

\subsubsection{Dondurulmuş Gıda}

Restoran işindeki adımlarda olduğu gibi, yemek yapma sürecindeki adımları oluşturalım. Müşteri markete gider. Mevsimine göre gıda ürünlerini satın alır, eve taşır ve pişirir.

Bu sürecin zıtlıkları birçok konsepti üretir. Müşteri markete gitmez de market müşteriye giderse e-ticaret sektörü başlar. E-ticaret sektörü bilgi işlem teknolojilerini ve kargo sektörünü doğurur.

Mevsimsel gıda yerine donmuş gıda alınır. Böylece mevsimlere bağlı olmaksızın bütün gıdalar tüketilebilir. Ertelenmiş tarihte yemek üzerine geçiş sağlanırsa fiyatlar düşürülmüş, gida fiyatlarındaki oynaklık azaltılmış ve dondurucu teknolojileri geliştirilmiş olur.

Pişirme süreçleri adımlanırsa zıtlıklarından birçok yeni konsept ortaya çıkar. Buna işlenmemiş malzeme yerine önceden yarı pişirilmiş ürünler veya tüm malzemeleri ölçüleriyle hazırlanıp sadece firına konup pişirilecek ürünler örnek verilebilir.

Şekil 3. Yemek Pişirme İş Süreci Adımları

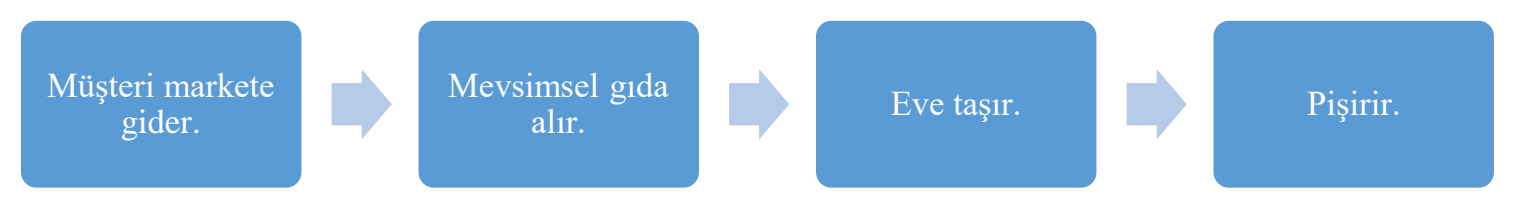




\subsubsection{ATM ve Online Bankacılık}

Bankacılıkta müşteri bankaya gider, parasını taşır ve ödemelerini yapar. Zıtlık prensibinden yola çıkarak duvarsız, personelsiz ve kasasız bankacılık kavramı üretilir. Müşterilerin bankaya gitmesi yerine zıtlıklar bulunarak ATM ve online bankacılık sistemi geliştirilir. Bu sayede zamandan ve maliyetten tasarruf sağlanırken yeni dağıtım kanalları oluşturulur.

Şekil 4. Bankacılık İş Süreci Adımları

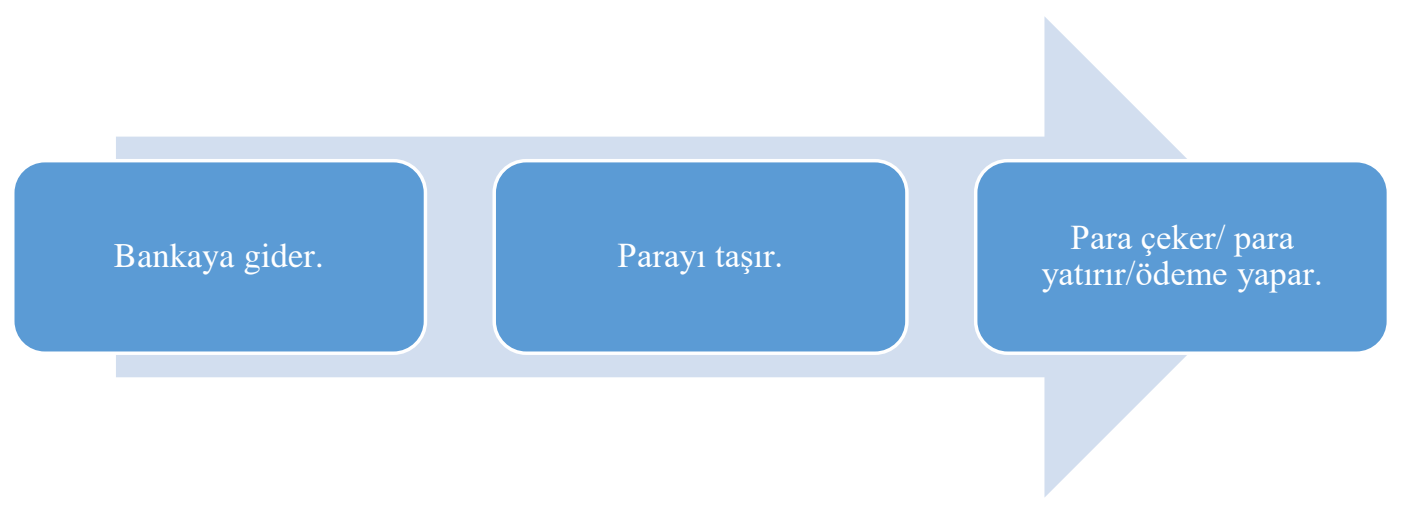

\subsection{0’un Gücü}

10’un gücü yönteminde, "Mevcut şartlar 10 misli veya 10 'da bir oranında yeniden şekillenseydi ne yapılırdı?" sorusuna cevap aranır.

\section{Kullanılırken dikkat edilecek hususlar:}

- Konunun belirlenmesi

- Konunun hangi unsurlarının 10 ile çarpılacağının ve bölüneceğinin belirlenmesi

10 ile çarpımda daha iyi müşteri hizmetleri (kalite), 10’a bölünmede maliyetlerin düşürülmesi (etkinlik) hedeflenir.

\subsubsection{Organizasyonların Yeniden Yapılanması: Kaynak Azaltma ve Artırma}

120 kişinin çalıştığı birim 12 kişiye düşürülse ve verilen hizmetin kalitesi azalmasa hizmet verilmeye nasıl devam edilir? Burada etkinlik kavramı ön plana çıkar. Kalite bozulmadan daha az kişiyle maliyetlerin düşürülmesi amaçlanır ve yeni projelerin alınması için mevcut birim çalışanlarının farklı bölümlere kaydırılması hedeflenir.

Personel sayısı 1200 kişiye çıkarılsaydı müşterilere hangi ek hizmetler verilebilirdi? Burada müşteri memnuniyeti ve kalite ön plandadır. Rakiplere göre daha iyi ve mükemmel hizmetler vermek için neler yapılabileceği tartışılır. Sonrasında düşünülen yeni hizmetlerin aynı kaynak miktarıyla (120 kişi) nasıl gerçekleştirilebileceği kurgulanır. Bu süreç yeni bir teknolojinin, ürünün ve organizasyon yapısının tekrar gözden geçirilmesi ile sonuçlanabilir.

\section{SONUÇ}

Fikir üretme farklı perspektif kazanılarak olur. Bu çalışmada perspektif değişimi için üç metot üzerinde duruldu: Alternatif dünyalar, zıtlıklar, 10’un gücü.

Alternatif dünyalarda sorunun çözümü için diğer sektörlerden, mesleklerden, mekânlardan, işletmelerden ve markalardan ilham alınır. Video kiralama, eğitim, bankacılık ve hastane olmak üzere dört sektörde alternatif dünyalar metoduyla yeni fikirler geliştirildi.

Netflix, sistemini kurmak için Amazon.com'dan, spor merkezlerinden ve DVD teknolojisinden faydalandı. Böylece müşterilerin video dükkânlarına gidip video kiraladığında ortaya çıkan zaman kaybını ve zamanında geri getirmediği vakit alınan ceza sistemini ortadan kaldırdı. Netflixte müşteri online sipariş verir, müşteriye 
video postalanır ve müşteriden aylık abonelik ücreti alınır. Videolarını geri gönderdiklerinde müşteriler yenilerini alabilirler. Sonuçta video kiralama sektörünün devi Blockbuster gelişmeleri çok geç takip ederek iş modelini Netflixe kaptırdı ve dev firma iflas etti.

Kalabalık sınıflarda derslerin etkin bir şekilde nasıl verilebileceği sorununu McDonalds/Starbucks/Swissotel olsaydı nasıl çözerdi? Bu soruya cevap aranırken inovasyon tetiklenmiş olur. Her biri farklı unsurlardaki problemlerin çözümünde ilham verebilir. McDonald'sta olduğu gibi ders materyalleri, eğitim ve notlamanın standart, kısıtlanmış ve seri olması; Starbucksta olduğu gibi öğrencilerin grup hâlinde çalışması ve notlamada öğretmene destek olması ve Swissotelde olduğu gibi geri kalmış öğrencilerin kişiye özel dersle ana gruba yetiştirilmeye çalışılması gibi çözümler üretilir.

Bir bankada, genç insanlar için bütçeleme yapılması konusunda yardımcı olmak üzere sağlı ve diyet merkezlerinde kullanılan takip modelleri kullanılabilir. Kilo takip programında yemeklerdeki kalorilerden alınan puanlar sayılarak kilo kaybetmeleri için insanlar motive edilirler. Kilo takip programındaki gibi, günlük olarak bütçelerdeki amaçlara ulaşılması için harcama ve kazançlar puanlanır ve takip edilir.

Sağlık kuruluşundaki hataları azaltmak için uçak bakım ve Formula 1 sisteminden faydalanılır. Uçak eğitmenleri kontrol listesini tek tek anlatırlar. Uçak bakımında, güvenlik dışında, uçurma öncesi her türlü konuşmanın yasaklandığı ve kâğıt üzerinde en küçük detayların bile üzerinden geçildiği görülür. Aynı sistem steril kokpit bölgesi altında hastanelerde uygulanıyor.

Zıtlıkta, süreçteki bir ya da iki adımın zıddı yerleştirilip diğer adımlarla yeni kombinasyonlar oluşturulur. Catering, dondurulmuş gıda, ATM ve online bankacılığın gelişimi zıtlık kavramları ile bulunmuştur.

Restoranda zıtlıklar üzerinde çalışıldığında mevcut mekânın müşterinin ayağına gitmesi catering endüstrisini doğuruyor.

Mevsimsel gıdanın tazeliğini muhafaza etme zorluğu üzerine zıtlıklarla çalışıldığında dondurulmuş gıda sektörü ortaya çıkıyor.

Müşterinin bankaya gitmesi yerine bankanın müşteriye gitmesi ATM ve online bankacılığı ortaya çıkarıyor.

10’un gücü yönteminde, "Mevcut kaynaklar 10 misli veya 10'da bir oranında yeniden şekillenseydi ne yapılırdı?" sorusuna cevap aranır.

Organizasyonların yeniden yapılanmasında 10'un gücü kullanıldığında mevcut kaynakta indirime gidilirse “etkinlik" ve kaynağın artışı ön görülürse "kalite” ön plandadır.

\section{KAYNAKÇA}

Beverly, R.I. (2013). Design Thinking for Entrepreneurs and Small Businesses: Putting the Power of Design to Work, New York: Apress.

Brown, T. (2008). “Design Thinking”, Harvard Business Review, 5(3), 56-65.

Brown, T. (2009). Change by Design: How Design Thinking Transforms Organizations and Inspires Innovation, New York: Harper Business.

Bushey, B. (2014). "Netflix CEO Confesses He Tried To Sell The Company To Blockbuster", Business Inside, http://www.businessinsider.com/blockbuster-missed-buying-netflix-2014-1, (Erişim Tarihi: 5 Mart 2018).

Diehl, M. ve Strpebe, W. (1987). "Productivity Loss In Brainstorming Groups: Toward the Solution of a Riddle”, Journal of Personality and Social Psychology, 53(3), 497-509.

Drucker, P. (2007). Management Challenges for the 21st. Century, New York: Butterworth-Heinemann.

Goodeeads. (2018). Einstein's Quote, https://www.goodreads.com/quotes/320600-we-can-not-solve-ourproblems-with-the-same-level, (Erişim Tarihi: 20 Aralık 2018).

Higgins, A., Hodgson, P. ve Travis, D. (2014). Bright Ideas for User Experience Researchers, London: Ebook. 
Kelley, T. (2005). The Ten Faces of Innovation: IDEO's Strategies for Beating the Devil's Advocate \& Driving Creativity Throughout Your Organization, New York: Doubleday.

Kelley, T. ve Kelley, D. (2014). Yaratıcı Özgüven İçimizdeki Yaratıcı Potansiyeli Serbest Bırakmak, İstanbul: Optimist Yayınları.

Kumar, V. (2012). 101 Design Methods: A Structured Approach for Driving Innovation in Your Organization, Chicago: Wiley.

Liedtka J. ve Ogilvie, T. (2011). Designing for Growth, New York: Columbia Business School.

Liedtka, J., King, A. ve Bennett, K. (2014). Solving Problems With Design Thinking, New York: Columbia Business School.

Luma Institute (2012). Human Centred Design, Philadelphia: Luma Institute Press.

Luma Institute. (2014). "Innovation of Taxanomy”, Harvard Business Review, Jan/Feb Volume, 40-46.

Owens, D. A., (2011), Creative People Must Be Stopped: 6 Ways We Kill Innovation. New York: Jossey-Bass.

Peterson, A., (2013). "Netflix Has Won: Blockbuster is Closing Its Last Retail Stores", The Washington Post, https://www.washingtonpost.com/news/the-switch/wp/2013/11/06/netflix-has-won-blockbuster-isclosing-their-last-retail-stores/?utm_term=.6927dc366432, (Erişim Tarihi: 20 Ağustos 2018).

Standford D. 2010. School. Power of Ten, https://dschoolold.stanford.edu/groups/k12/wiki/faf1d/powers_of_ten.html, (Erişim Tarihi: 21 Şubat 2018).

Sutton, B. (2004). What Is Creativity?, http://ecorner.stanford.edu/authorMaterialInfo.html?mid=1187, (Erişim Tarihi: 7 Mart 2015).

Sutton, B. (2007). Weird Ideas That Work: How to Build a Creative Company, New York, Free Press. 